American Journal of Pharmaceutical Education 2019; 83 (5) Article 6789.

\title{
RESEARCH
}

\section{Students' Perceptions on a Business Plan Assignment for an Ambulatory Care Pharmacy Elective}

\author{
Jessica Wilhoite, PharmD, ${ }^{\text {a,b }}$ Jessica W. Skelley, PharmD, ${ }^{\mathrm{c}, \mathrm{d}}$ Andrea Baker, PharmD, ${ }^{\mathrm{e}}$ \\ Kristina Traxler, PharmD, ${ }^{e}$ Jessica Triboletti, PharmD ${ }^{\mathrm{e}, \mathrm{f}}$ \\ ${ }^{\text {a }}$ Butler University College of Pharmacy and Health Sciences, Indianapolis, Indiana \\ ${ }^{\mathrm{b}}$ Community Health Network, Indianapolis, Indiana \\ c St. Vincent's East Family Medicine Residency Program, Birmingham, Alabama \\ ${ }^{\mathrm{d}}$ McWhorter School of Pharmacy, Birmingham, Alabama \\ ${ }^{\mathrm{e}}$ Butler University College of Pharmacy and Health Sciences, Indianapolis, Indiana \\ ${ }^{\mathrm{f}}$ Eskenazi Health, Indianapolis, Indiana \\ Submitted September 12, 2017; accepted June 14, 2018; published June 2019.
}

Objective. To evaluate a business-centered assignment implemented in a pharmacy elective course at two different institutions and analyze student perceptions of the delivery platforms used and the value and utility of the assignment.

Methods. The ambulatory care electives at Butler University and Samford University introduce students to the expanding role of the ambulatory care pharmacist, emphasizing business plan development for new ambulatory care pharmacy services. As part of the elective, students are asked to work in groups to complete a business plan for a new ambulatory care service of their choosing. A survey was conducted to assess student perceptions on the assignment.

Results. Of the 58 students who completed the business plan assignment, 49 completed the survey and were included in the data analysis. Overall, 100\% of Samford students and 97\% of Butler students either strongly agreed or agreed that the business plan was an innovative assignment unlike others completed in the curriculum. Samford students strongly agreed (100\%) that if asked by a future employer to develop a new pharmacy service, concepts learned from this assignment would be useful, compared to $59 \%$ of Butler students who felt this way. While both the web and written delivery platforms had identical learning outcomes, the written business plan was the approach that the majority of students were more comfortable using.

Conclusion. The business plan assignment was used as a method to familiarize students with the process of developing new ambulatory care pharmacy services. Based on survey results, the students perceived this to be an innovative assignment that allowed them to feel confident in developing and communicating ambulatory care business plans. As the practice of ambulatory care pharmacy expands, assignments such as this can be included in the pharmacy curriculum to meet the need for teaching effective business strategies to future pharmacists.

Keywords: pharmacy, education, ambulatory care, service development

\section{INTRODUCTION}

According to the American College of Clinical Pharmacy (ACCP), American Pharmacists Association (APhA), and American Society of Health-System Pharmacists (ASHP), there is an increasing demand for ambulatory care pharmacy services together with a growing number of patients with multiple chronic health conditions who re-

Corresponding Author: Jessica Wilhoite, Butler University College of Pharmacy and Health Sciences, 4600 Sunset Ave., Indianapolis, IN 46208. Tel: 317-957-9182. E-mail:

jwilhoit@butler.edu quire complex medication management. ${ }^{1}$ This growing field requires pharmacists and pharmacy students to be at the forefront of healthcare service development. ${ }^{1}$ While pharmacy curricula focuses heavily on clinical and professional skills, less time is typically spent on practice management and business-focused initiatives such as proposal development, managerial strategy, and health outcomes analysis. Elective courses, specifically in ambulatory care, tend to mirror this trend by focusing on disease-state management rather than business strategy analysis. ${ }^{2,3}$ However, practice sustainability is an important consideration in creating ambulatory care services and is often listed by 


\section{American Journal of Pharmaceutical Education 2019; 83 (5) Article 6789.}

both new and experienced practitioners as being a significant challenge. ${ }^{4}$ Additionally, the ASHP identified practice management skills as one of the four crucial elements of service in their guideline on minimum standards for ambulatory care pharmacy practice. ${ }^{5}$ This gap between classroom training and actual practice indicates a need for increased opportunities focused on practice management topics within pharmacy curricula, especially in the field of ambulatory care.

Elective courses within pharmacy curricula provide a unique opportunity for students to gain knowledge and experience in a specific field or clinical area of interest. There are some published examples of elective courses where business plan assignments have been incorporated. ${ }^{6,7}$ However, most were located within pharmacy management or entrepreneurship electives and typically focused on the development of services within a dispensing pharmacy; none have occurred in an ambulatory care elective designed to address the practice management challenges unique to this setting. ${ }^{8,9}$ Butler University College of Pharmacy and Health Sciences has offered an ambulatory care elective course since 2012 that takes place during spring semester and is open to third-year Doctor of Pharmacy (PharmD) students. Samford University McWhorter School of Pharmacy began offering an ambulatory care elective course in the fall semester in 2016 that is also open to third-year students. At both institutions, the purpose of the ambulatory care elective is to introduce students to the expanding role of ambulatory care pharmacists. Unlike other published examples of ambulatory care electives that focus on disease state topics, the focus of the elective courses offered at Butler and Samford is on designing and developing ambulatory care pharmacy services through creating a business plan, assessing and appropriately educating patients, and communicating with other healthcare professionals. ${ }^{10}$ Students are also expected to participate in activelearning coursework to further develop skills in communication, problem solving, and interprofessional team collaboration. The content for both programs consists of both lecture and case-based studies.

The ambulatory care business plan assignment provided an opportunity for both the pharmacy students and the two pharmacy schools to address two important outcomes in pharmacy education. The Center for the Advancement of Pharmacy Education (CAPE) 2013 Educational Outcomes provide guidance on pharmacy curriculum framework as well as influence curricular change. ${ }^{11}$ The CAPE outcomes reflect a wide variety of critical pharmacy knowledge and necessary skills for future pharmacists. The ambulatory care business plan assignment described here meets CAPE outcomes 4.3.5. and 4.3.6. (innovation and entrepreneurship), which advise that students "engage in innovative activities by using creative thinking to envision better ways of accomplishing professional goals" by applying business skills within a simulated entrepreneurial activity. ${ }^{11}$ While the need for clinical knowledge and development remains, the growing healthcare industry values professionals that can provide solutions. The business plan assignment helps to develop a unique subset of skills reflected in the CAPE outcomes that are needed to address this challenge in a rapidly growing area of practice. The purpose of this research was to evaluate the business-centered assignment and analyze student perception of its value and utility.

\section{METHODS}

The business plan assignment was a group-based, mandatory assignment in which students were asked to develop a business plan for a new ambulatory care pharmacy service of their choosing. Creating the business plan included: conducting a market analysis of the chosen service, developing a marketing plan, developing a budget to sustain the service, writing a three-year pro forma statement, and conducting a break-even analysis. At both institutions, this assignment was the focus for six weeks of the course. Instruction was given to students regarding the components and structure of a business plan prior to their development of services. Students were also given a three-hour class period to work on the assignment with their group. This assignment was meant to simulate the task that an ambulatory care pharmacist would face when trying to effectively implement, justify, and sustain a new clinical service. Both institutions required the groups to give an oral presentation and submit a written plan for the assignment. In the oral presentation, the students were to demonstrate the value of the service to the institution as well as the financial stability and sustainability of their service. Students presented their plan to classmates and faculty members who posed as health institution administrators. Samford University students developed a traditional, written business plan, which they submitted via the course's learning management system. In contrast, Butler University students designed and developed a website on which to present the content of their business plan. Instructions for the business plan assignment were given to students in the course syllabus and discussed in lectures. This project emphasized the development of creativity and business skills that are considered crucial for ambulatory care pharmacy practice. 


\section{American Journal of Pharmaceutical Education 2019; 83 (5) Article 6789.}

The business plan assignment was evaluated using two rubrics, one for the business plan itself and the other for the oral presentation proposal. The rubrics used at the two schools of pharmacy were identical except for the inclusion of a website design component at Butler University (these rubrics are available upon request). The four critical areas that were evaluated for the business plan were writing, layout or structure, use of information sources, and images or visual content. The written business plan was worth 100 points and included the following areas of evaluation: executive summary, purpose, background, introduction, program description, strength/ weakness/opportunities/threats (SWOT) analysis, marketing plan, financial projections, clinical logistics, creativity and innovation, and conclusion or summary. The oral presentation was worth 25 points and included the following critical areas: sales pitch, passion for service and persuasiveness, service details, presentation content, appropriate public speaking skills, evidence of all group member participation, and time limits met. The oral presentation rubric also included two open-ended questions on strengths and areas of improvement so that groups received personalized feedback.

The participants in this study were the students enrolled in ambulatory care pharmacy electives at Butler University during the spring semesters of $2015(n=12), 2016$ $(\mathrm{n}=7)$, and $2017(\mathrm{n}=21)$ and Samford University during the fall semester of $2016(n=18)$, for a total of 58 students. This study used surveys as the primary method of research to evaluate student perception of the business plan assignment. Students completed the survey on a volunteer basis and their participation had no impact on their score for the assignment or their grade in the elective course. All students enrolled in the elective course were invited to participate in the survey. The survey was completed anonymously online via SurveyMonkey (SurveyMonkey Inc, San Mateo, California, www.surveymonkey.com) and took approximately 10-15 minutes. The questions were based on the objectives of the course material, the strengths and weaknesses of the business plan assignment, and the perceived value and applicability of the content to clinical settings. Responses were recorded on a Likert scale with four options ranging from strongly agree to strongly disagree. There were also three open-ended questions for which students typed in a response with no limit on characters. The Samford University survey consisted of eight Likert-scale questions and three open-ended questions. The Butler University survey consisted of 11 Likert-scale questions and three open-ended questions. Students from Samford University were excluded from answering questions 3, 4, and 6 of the survey as these items were specific to the use of the website as the medium for presentation.
Students had to sign a consent statement at the beginning of the survey that reiterated that completion of the survey would have no impact on their course assignment grade and served as voluntary consent for the anonymous results to be used for research purposes. This study was approved by the institutional review board at the participating universities.

\section{RESULTS}

Of the 58 students who completed the business plan assignment, 49 (84.5\%) completed the survey instrument and were included in the data analysis. Of the 49 respondents, the $32(65 \%)$ Butler University students used the web-based platform, while 17 (35\%) Samford University students completed a traditional written business plan. The number of students who participated in both the assignment and survey each semester is as follows: 13 $(26.5 \%)$ in spring $2015,5(10.2 \%)$ in spring 2016, 17 (34.7\%) in fall 2016, and $14(28.6 \%)$ in spring 2017.

Following the business plan assignment, 17 (100\%) Samford University and 30 (96.8\%) Butler University students either agreed or strongly agreed that the assignment was innovative and unlike projects they had completed in other courses. Additionally, $100 \%$ of the Samford University students and $74.2 \%$ of the Butler University students agreed or strongly agreed that the amount of time spent on this project was appropriate and comparable to other group projects they had completed. Although the majority (65.3\%) of Butler University students agreed or strongly agreed that the time allotted during class to work on the business plan assignment was beneficial, $20.4 \%$ did not believe that the time provided was sufficient. Upon completing the assignment, the following percentages of students agreed or strongly agreed that they could perform the designated course objectives: identify the role of the ambulatory care pharmacist in service development and/or expansion: $100 \%$ of both Samford and Butler University students; design and develop a protocol for a new ambulatory care pharmacy service: $100 \%$ of Samford University and $90.3 \%$ of Butler University students; and create and verbally communicate a business plan for an ambulatory care pharmacy service: $100 \%$ of Samford University and $93.5 \%$ of Butler University students. All of the data obtained from the survey results is displayed in Table 1.

The open-ended questions assessed overall interest in ambulatory care, the group dynamic of the assignment itself, and use of the website platform. All (100\%) of Samford University students and over $73 \%$ of Butler University students noted a positive and increased interest in the practice of ambulatory care pharmacy after completing the assignment, while others felt they could use the 
American Journal of Pharmaceutical Education 2019; 83 (5) Article 6789.

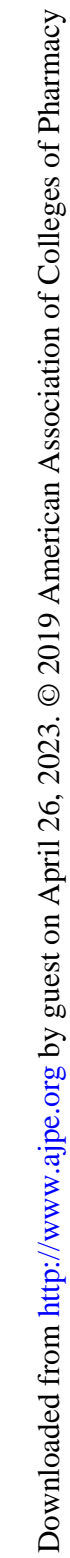

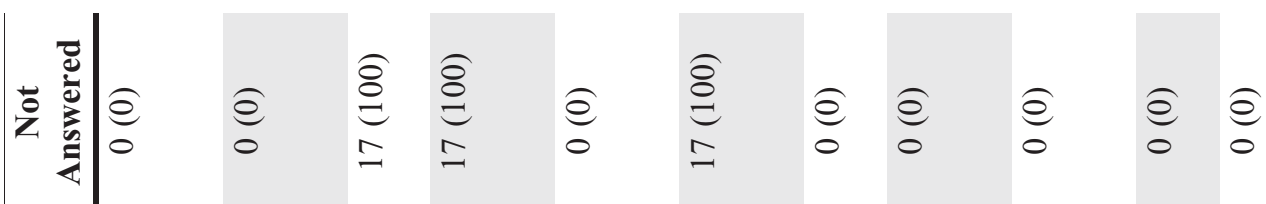

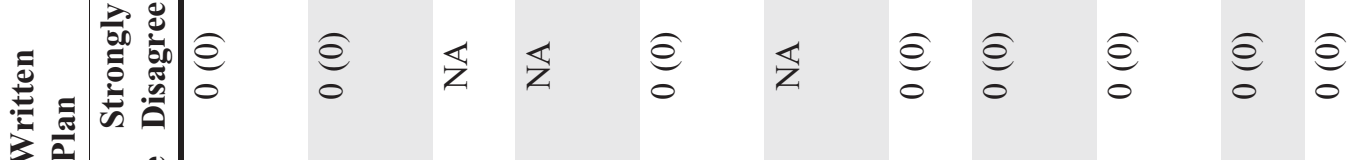

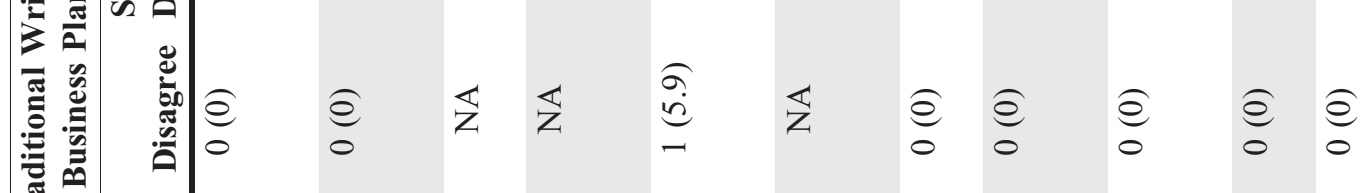

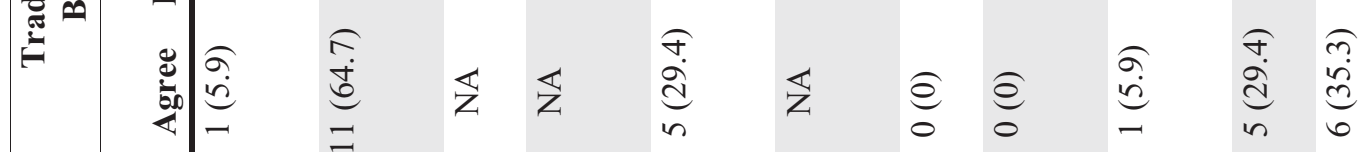

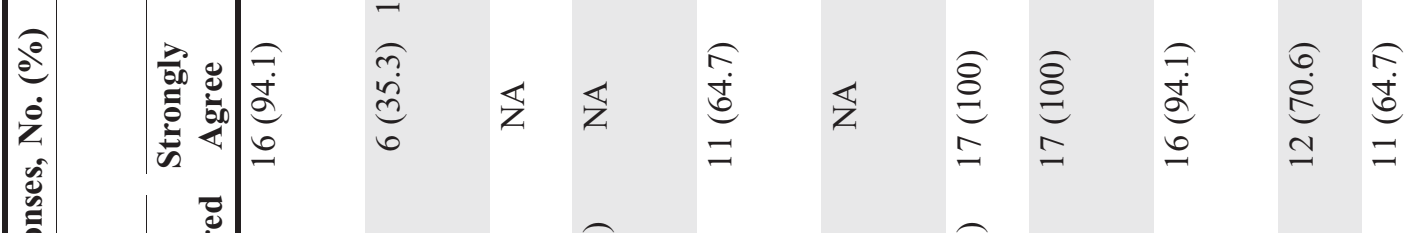

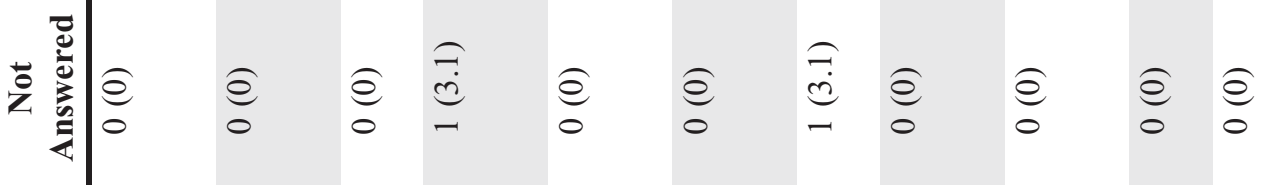

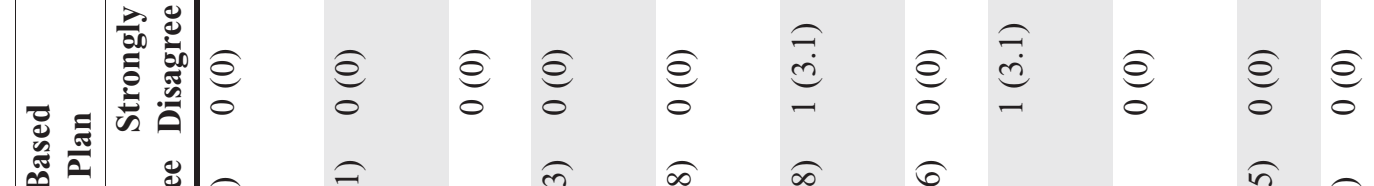

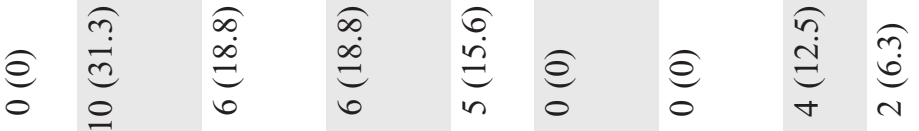

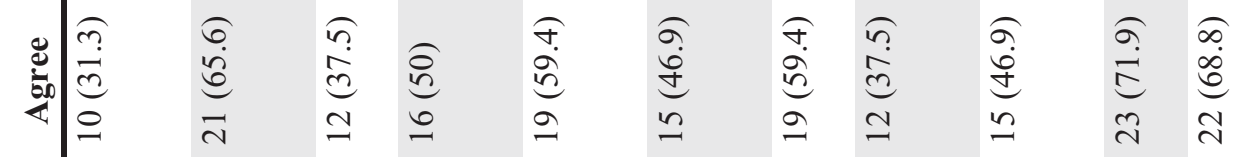

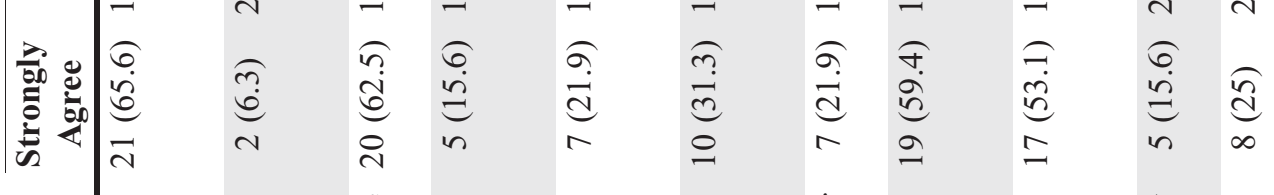

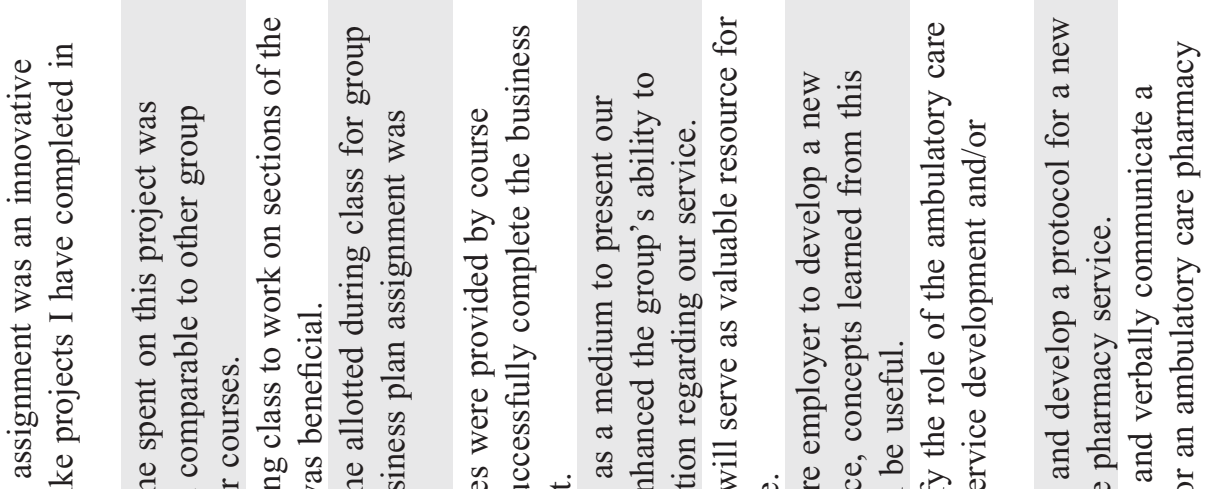
焉. 


\section{American Journal of Pharmaceutical Education 2019; 83 (5) Article 6789.}

skills developed from the project in other fields of pharmacy. Additionally, over $88 \%$ of Samford University students and over $96 \%$ of Butler University students overwhelmingly agreed that the assignment itself should be a group-based project because of the complexity of the task and the workload required for a single semester. Lastly, the website design used was the preferred medium by $60 \%$ of the students who used it as they believed it was innovative and a unique way to present the service. The second most common answer regarding the presentation medium was that students did not have a strong preference as to which platform they were required to use. Table 2 includes the specific open-ended questions asked in the survey.

Because the survey was anonymous, there was no way to match students' responses with their grade on the assignment. For this reason, the reported assignment grades are the average for all students enrolled in the ambulatory care electives. In the spring of 2015, each student at Butler University was given one score (average of $92.2 \%$ ) that encompassed both their business plan and oral presentation. For the remainder of the semesters at Butler University, students received one score for the business plan itself (average of 94.4\%) and a second score for their oral presentation (average of 92\%). Similarly, students at Samford University received a score for their written business plan (average of 96.9\%) and a second score for their oral presentation (average of 94\%). Additional data regarding the project grades of students are provided in Table 3.

\section{DISCUSSION}

Previous studies examining pharmacy ambulatory care electives have focused on students' development of clinical skills and therapeutic knowledge, ability to obtain a pharmacy postgraduate residency in ambulatory care, and perceptions on their ability to provide clinical patient care services. ${ }^{2,3,10,12,13}$ While clinical knowledge is a crucial component of the pharmacy curriculum, practical problem-solving skills and creative development experience are just as vital to nurturing future professionals and their ability to expand the practice of pharmacy. Our study sought to compare and contrast two methods of business plan delivery for ambulatory care services. The CAPE Educational Outcomes include items that focus on innovation and creative thinking, which can otherwise be difficult to implement in pharmacy curriculum.

This is the first study to analyze student perceptions of business-focused learning within pharmacy curricula, specifically for ambulatory care service development comparing a web-based platform and a written business plan approach. Through completion of a business plan, Butler University students (web-based platform) and Samford University students (traditional business plan) were able to gain both practical and conceptual skills needed for development of ambulatory care pharmacy services. Students at both schools had positive perspectives regarding the assignment, though fewer Butler University students felt there was an appropriate allocation of time to complete the assignment. When considering the nature of the website-based approach, Butler students were tasked with additional hurdles to overcome. Although the assignment was more time consuming, the majority of Butler students still preferred the websitebased platform and felt it provided them the means to easily share their completed project. In a healthcare system constantly implementing electronic resources, the website-based platform may provide a greater return on investment in the long term. Of note, all survey participants from both cohorts felt they could identify the role of the ambulatory care pharmacist in service development and/or expansion, illustrating the equivocal perceptions and value of the business plan assignment.

Students at both schools indicated confidence in designing and developing a protocol for a new ambulatory care pharmacy service as well as creating and verbally communicating a business plan. When considering which delivery method proves to be more beneficial to student learning, similar findings resulted. Both methods were conducive to educating students on the importance of business plan development, and implementing either design would facilitate positive student learning outcomes.

Faculty have adapted the assignment based on student feedback, and it will continue to remain a required project for the course. The overwhelmingly positive response regarding the perceived value of this assignment

Table 2. Open-Ended Survey Questions

Describe how this project has impacted your current level of interest in ambulatory care pharmacy.

If you were given the choice, would you prefer to work on this project in a group, as an individual, in pairs, or any other groupings?

Please describe your preference.

If you were given the choice, would you present the business plan in a written format, as a website, or other? Please explain your reasoning. 


\section{American Journal of Pharmaceutical Education 2019; 83 (5) Article 6789.}

Table 3. Business Plan and Oral Presentation Grades

\begin{tabular}{|c|c|c|c|c|c|c|}
\hline Semester & University & $\begin{array}{c}\text { Students } \\
\text { Enrolled } \\
\text { (No.) }\end{array}$ & $\begin{array}{c}\text { Business } \\
\text { Plan } \\
\text { Score, } \\
\text { Average \% }\end{array}$ & $\begin{array}{c}\text { Business } \\
\text { Plan } \\
\text { Score, } \\
\text { Range, \% } \\
\end{array}$ & $\begin{array}{c}\text { Oral } \\
\text { Presentation } \\
\text { Score } \\
\text { Average, \% } \\
\end{array}$ & $\begin{array}{c}\text { Oral } \\
\text { Presentation } \\
\text { Score } \\
\text { Range, \% } \\
\end{array}$ \\
\hline Spring 2015 & Butler & 12 & 92.2 & $87-100$ & $\mathrm{a}$ & $\mathrm{a}$ \\
\hline Spring 2016 & Butler & 7 & 94.7 & $92-96$ & 94.7 & $92-96$ \\
\hline Fall 2016 & Samford & 18 & 96.9 & $96-97.3$ & 94 & $92-96$ \\
\hline Spring 2017 & Butler & 21 & 94.3 & 91-99 & 91.2 & $84-96$ \\
\hline
\end{tabular}

${ }^{a}$ The oral presentation did not have a score separate from the written business plan at Butler University in 2015

reflects the importance of non-clinical skill development related to ambulatory care pharmacy. In addition to skills gained from completing the business plan, there was also a benefit to using a website as the platform for presentation at Butler University. Overall, students appreciated using a medium outside of traditional writing that allowed them more creative freedom. After completion, many students believed they had created a unique project that could be shared with future employers or residency program directors.

There are limitations to this study that need to be considered. First, the business plan assignment was implemented in an ambulatory care elective course. Students enrolled in elective courses typically have more vested interest in the content and tend to be more positive toward that particular pharmacy specialty. Second, having the survey completed on a volunteer basis allowed students to skip questions, which resulted in some items having a lower response rate than others. Finally, while we compiled study data from more than one pharmacy school to increase the generalizability of our findings, having input from only two pharmacy schools means the data may not be an accurate reflection of all pharmacy students' perceptions. Efforts were made to limit variability between the two locations by using identical rubrics and survey instruments. However, inclusion of multiple learning institutions can affect survey responses by way of variations in geographic region, pharmacy culture, instructor teaching style, and lecture materials.

Feedback students provided from 2015 to 2017 allowed the assignment to evolve. Some examples of how the assignment has changed over time include students receiving a separate grade for the oral presentation and students being allowed to choose the clinical service for which they want to write a business plan. Even with these changes, students continue to comment that making assumptions about their fictional clinical service is the most difficult part of the assignment. For example, when completing the needs assessment for their fictional ser- vice, true institution-specific data did not exist and the need for the service was presumed based on extrapolations of local data. Based on this feedback, faculty members at Butler University reached out to various local health institutions to determine their interest in being involved in this project through provision of ambulatory care clinical services currently in the pipeline to be developed. By assessing the needs for an ambulatory care clinical pharmacy service within a local institution, there is benefit to both parties. Students have the opportunity to propose a real service that could potentially be implemented and would have real numbers on which to base their financial projections and expectations as opposed to making assumptions. Additionally, the local institutions would receive a business plan from a new perspective which could be used to justify new personnel. Further research and evaluation is needed to determine the value of partnering with local institutions for this assignment.

\section{CONCLUSION}

With the increasing demand for ambulatory care pharmacy services, future pharmacists need to be prepared for the business development and strategy implementation needed to build and maintain a successful practice. Additionally, this study demonstrates that multiple methods may be executed to achieve the same goal. Both the website-based platform and the traditional, written business plan models proved to be positively perceived by students, although students felt the website-based platform was more time-consuming to develop. Pharmacy curricula typically do not focus on clinical service development; however, this study demonstrates that students perceive confidence in designing and implementing a clinical service in an ambulatory care setting after completing a business plan assignment.

\section{REFERENCES}

1. A petition to the Board of Pharmaceutical Specialties requesting recognition of ambulatory care pharmacy practice as a specialty. American College of Clinical Pharmacy, American Pharmacist 


\section{American Journal of Pharmaceutical Education 2019; 83 (5) Article 6789.}

Association, American Society of Health-System Pharmacy. https://www.accp.com/docs/positions/petitions/

AmbulatoryCarePetitionExecutive_Summary.pdf. Accessed June 13, 2017.

2. Isaacs D, Roberson CL, Prasad-Reddy L. A chronic disease state simulation in an ambulatory care elective course. Am J Pharm Educ. 2015;79(9):Article 133.

3. Zingone MM, Franks AS, Guirguis AB, et al. Comparing teambased and mixed active-learning methods in an ambulatory care elective course. Am J Pharm Educ. 2010;74(9):Article 160.

4. Weber ZA, Skelley JW, Sachdev G, et al. Integration of pharmacists into team-based ambulatory care practice models. $\mathrm{Am} J$ Health-Syst Pharm. 2015;72:745-751.

5. American Society of Health-System Pharmacist Guidelines: Minimum Standard for Ambulatory Care Pharmacy Practice. Am J Health-Syst Pharm. 2015;72:1221-1236.

6. Moultry AM. A mass merchandiser's role in enhancing pharmacy students' business plan development sills for

medication therapy management services. Am J Pharm Educ.

2011;75(7):Article 133.

7. Skomo ML, Kamal KM, Berdine HJ. A required course in the development, implementation, and evaluation of clinical pharmacy services. Am J Pharm Educ. 2008;72(5):Article 109.

8. Perepelkin J. Redesign of a required undergraduate pharmacy management course to improve student engagement and concept retention. Am J Pharm Educ. 2012;76(10):Article 201.

9. Hicks C, Siganga W, Shah B. Enhancing pharmacy student business management skills by collaborating with pharmacy managers to implement pharmaceutical care services. Am J Pharm Educ. 2004;68(4):Article 94.

10. Vincent AH, Weber, ZA. Instructional design and assessment: an elective course on current concepts in adult ambulatory care. Am J Pharm Educ. 2014;78(10):Article 183.

11. Medina MS, Plaza CM, Stowe CD, et al. Center for the Advancement of Pharmacy Education (CAPE) educational outcomes 2013. Am J Pharm Educ. 2013;77(8):Article 162.

12. Messinger NJ, Buring SM. Development of an ambulatory care pharmacy elective by a second-year pharmacy resident. Curr Pharm Teach Learn. 2015;7(5):676-683.

13. Barnes KD, Maguire M, Bennett MS. Impact of an elective course in community and ambulatory care pharmacy practices on student perception of patient care. Am J Pharm Educ.

2015;79(7):Article 104. 